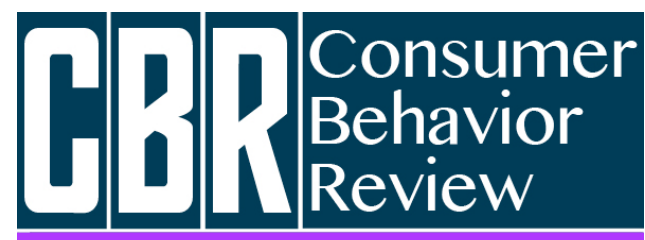

Revista Comportamento do Consumidor
Costa, D. \& Falcão, R. F. (2018). O valor percebido pelos usuários na troca de tempo: o caso Bliive. Consumer Behavior Review, 2(Special Edition), 19-32.
ISSN: 2526-7884

Editor: Prof. Dr. Marconi Freitas da Costa

Email da revista: cbr@ufpe.br
Avaliação: Double blind review

Recebido: 31 de maio de 2018

Aceito: 27 de julho de 2018

\title{
O VALOR PERCEBIDO PELOS USUÁRIOS NA TROCA DE TEMPO: O CASO BLIIVE
}

\author{
Dharan Costa \\ Roberto Flores Falcão
}

\begin{abstract}
Dharan Costa é Bacharel em Administração pela Fundação Escola de Comércio Álvares Penteado - FECAP. E-mail: dharancosta@gmail.com.

Roberto Flores Falcão é Doutorando em Administração pela Faculdade de Economia, Administração e Contabilidade da

Universidade de São Paulo - FEA/USP.

E-mail: titofalcao@hotmail.com.

Os autores agradecem aos avaliadores pelos comentários para melhoria do artigo.
\end{abstract}

\begin{abstract}
Resumo
A atual revolução tecnológica tem potencializado o surgimento de empresas dentro da economia compartilhada que privilegiam o acesso ao invés da propriedade. Como resposta ao hiperconsumismo e à crise econômica global, surge um novo padrão de comportamento do consumidor chamado de lifestyle colaborativo, que propõe a troca de conhecimento, habilidades e tempo entre pessoas. Nesse contexto, o presente trabalho se propõe a entender o valor percebido dos usuários que participam de uma plataforma de troca de tempo, a Bliive. Para tanto, foi realizada uma pesquisa qualitativa exploratória que, por meio de entrevistas com treze usuários, analisou três dimensões do valor percebido: funcional, emocional e social. A análise revelou que as pessoas se engajam na rede porque a plataforma possibilita a conexão entre pessoas com interesses em comum, porém o motivo que as mantêm no sistema é o senso de comunidade e o lifestyle colaborativo. Palavras-chave: Economia compartilhada, Troca de tempo, Valor percebido.
\end{abstract}

\section{INTRODUÇÃO}

O mundo moderno tem em sua história três grandes revoluções que mudaram os mercados produtivos: a revolução agrícola, a revolução industrial, e a revolução tecnológica, focada na informação e inovação. Segundo Gupta e Govindarajan (2003), a função principal da inovação é a criação de valor para as organizações e seus stakeholders, hoje um dos fatores mais importantes para as empresas desenvolverem a competitividade em um mercado que está passando por inúmeras mudanças. Autores como Schwab (2016) acreditam que o mundo moderno está vivendo uma quarta revolução que une os sistemas 
digitais, físicos e biológicos em velocidade exponencial maximizando o bem-estar do ser humano.

É nesse contexto de inovação que o consumo colaborativo ganha forças como uma alternativa sustentável ao movimento de hiperconsumo. Segundo Botsman (2010), a combinação entre a crise mundial, a pressão para solucionar problemas ambientais e a renovação da crença nas comunidades por meio das plataformas digitais impulsionaram o surgimento das primeiras empresas da economia colaborativa moderna. Baseadas na troca, no compartilhamento e aluguel de bens ou serviços, empresas e startups estão conectando milhões de pessoas que possuem tais bens ou serviços com milhões de outras pessoas que desejam o acesso aos mesmos.

Evidencia-se uma mudança no padrão de consumo das pessoas. Uma mudança na lógica do prestígio de se ter bens (de sua propriedade) para o prazer do acesso a eles, de usufruir de seus benefícios durante um dado horizonte temporal. Ao contrário do consumo tradicional, o consumo na economia compartilhada baseia-se em pessoas que trabalham de forma colaborativa, compartilham ideias e práticas, e geram interações, promoções e venda de produtos de forma cooperativa (Botsman \& Rogers, 2010).

Nesse contexto, percebe-se uma redução do comportamento individualista e a distinção das pessoas conforme suas posses (Botsman \& Rogers, 2010), revolucionando e redefinindo as relações entre pessoas e organizações por desafiarem as noções estabelecidas de posse e consumo. Ao conectar pessoas diretamente, esses movimentos transformam indivíduos em empreendedores por serem simultaneamente consumidores e produtores.

Uma nova forma de relacionamento entre os atores da troca é criada e passa a ser definida pela reputação, pela comunidade, por aquilo que podem acessar, pelo modo como compartilham e doam. Os consumidores passam a ser mais protagonistas em suas compras e no processo de decisão, e assim buscando pagar pelo acesso ao produto e experiência de tê-los temporariamente, ao invés de adquiri-lo (Bardhi \& Eckhardt, 2012). A consequência disso foi a criação de um novo entendimento do que é valor, quando relacionado ao ato de consumir. Fazendo com que empresas tradicionais de grandes indústrias, como a de turismo, finanças, mobilidade, alimentação, entretenimento e outras tantas estejam sendo colocadas em cheque, pelos modelos de negócios que atendem a essa nova tendências de consumo do mundo.

Prahalad e Ramaswamy (2004) citam que, para que as empresas sejam competitivas no cenário atual, é preciso efetuar alterações no processo de criação de valor, o que significa também mudar a interação entre cliente e empresa. $\mathrm{O}$ valor percebido pelos compradores sobre as ofertas pode ser a diferença entre empresas competitivas e as com problemas de sobrevivência. Quanto maior o valor percebido, maior tende a ser sua disposição para adquirir produtos.

A partir do exposto, o presente estudo se propõe a avançar a compreensão sore o comportamento do consumidor sob a ótica do valor percebido no contexto da economia compartilhada, investigando o lifestyle colaborativo que, de acordo com Botsman (2010), é o compartilhamento de dinheiro, habilidades e tempo. Mais especificamente, o objetivo desta pesquisa é compreender as dimensões do valor percebido por integrantes da rede Bliive - uma rede social colaborativa de troca de tempo - e apontar qual dimensão se mostra mais relevante aos usuários da plataforma.

A ideia de compartilhar bens ganha destaque no século 18 , com a implementação de bibliotecas comunitárias em pequenas vizinhanças. Com o desenvolvimento da internet e o conforto com as compras online, esse mesmo princípio começou a acontecer em uma escala global. Segundo a projeção da Price Waterhouse Coopers, PwC (2014), o mercado de compartilhamento de bens crescerá suas receitas de $\$ 15$ bilhões de dólares em 2013 para $\$ 335$ bilhões em 2025, é um aumento de 22 vezes em 12 anos, o faturamento quase dobra (86,11\% de crescimento) todos os anos.

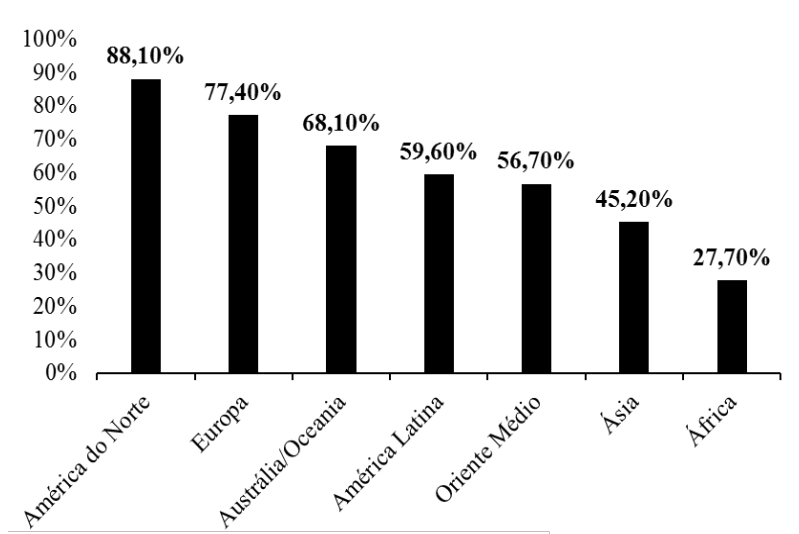

Fonte: Internet World Stats (2018)

Gráfico 1. Taxas de penetração da Internet no Mundo (março de 2017) 
Esse crescimento da economia colaborativa está acontecendo devido ao avanço das novas tecnologias de comunicação, especialmente ao crescimento do acesso à internet, conforme gráfico 1, possibilitaram novos entrantes em diferentes países.

A disseminação do uso de smartphones que já chega a mais de 7,4 bilhões de aparelhos, conforme gráfico 2, deixou os consumidores permanentemente online, possibilitando $\mathrm{o}$ suprimento da oferta do mercado da economia compartilhada (Credit Suisse, 2015).

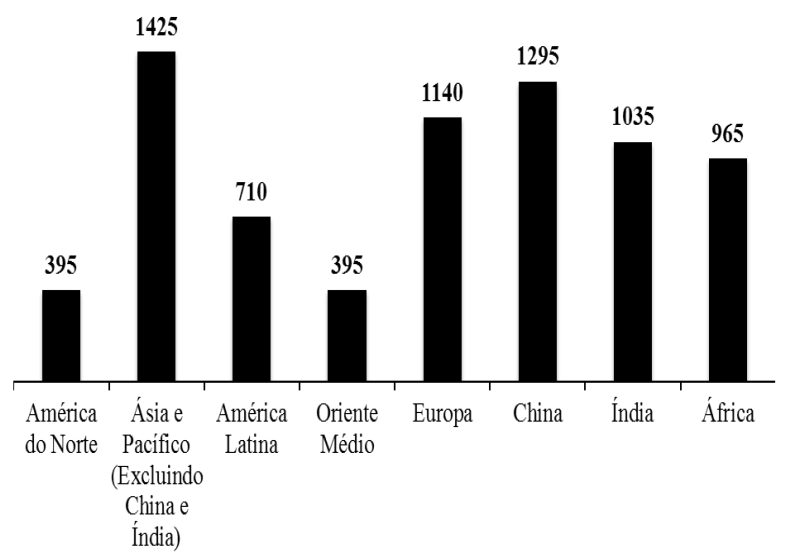

Fonte: Ericsson Mobility Report (2016)

Gráfico 2. Linhas de aparelhos móveis (em milhões)

Esses resultados reforçam a ideia de que a economia colaborativa aumenta o conforto, pela praticidade e facilidade de acesso das plataformas online; existe também um aumento da confiança, por meio de avaliações entre usuários e provedores dos serviços prestados ou bens consumidos; e uma redução dos custos de transação dos bens e serviços já que as empresas utilizam da colaboração de seus usuários de diversas formas (Exemplo: Wikipedia, que utiliza do conhecimento de seus usuários obter conteúdo para o site); em sua maioria, o compartilhamento pode apresentar soluções sustentáveis para a sociedade (Exemplo: Bla Bla Car, que une pessoas com o mesmo destino e assim reduz os custos de ambas).

É interessante destacar que as pessoas que participam da economia colaborativa não estão apenas interessadas em reduzir seus gastos, fatores como sentir-se útil, conhecer novas pessoas e prestar algum tipo de suporte, são citados em 40\% ou mais vezes na pesquisa da PwC (2014).

Segundo a PwC (2014) os consumidores estão cada vez mais dispostos a usar as plataformas da economia compartilhada. Em sua pesquisa, descobriu-se que apenas $19 \%$ da população dos Estados Unidos usufrui da economia compartilhada e $72 \%$ dos que ainda não usam, se veem como consumidores da economia compartilhada nos próximos anos.

Dentro da gama de empresas que trabalham com parte do estilo de vida colaborativo, a Bliive se mostra relevante pela diferenciação em sua proposta de troca de tempo (experiências, conhecimentos) entre seus usuários sem a necessidade de monetizar as transações. Esse modelo de negócio, de banco de tempo, é ainda pouco explorado em pesquisas no país, e como a Bliive é uma organização brasileira que está sendo levado para o mundo é necessária uma investigação mais profunda sobre a comunidade formada na rede e a utilização feita por seus usuários.

A proposta da empresa se mostra inovadora justamente por fazer uma quebra dos conceitos capitalistas de troca. São valores resgatados da cultura do escambo (BBC, 2012), que incentivados pela crise ambiental, econômica e das relações humanas ganha força e surge como alternativa para as relações de trocas de bens e serviços.

Desta maneira, extinguindo-se a necessidade de dinheiro, a Bliive propõe para seus usuários, aqueles com acesso à internet, um valor de troca diferenciado, o tempo. Dentro desse modelo de troca de tempo existe uma contribuição teórica a ser feita, já que os estudos a respeito de troca de tempo na economia colaborativa ainda são escassos e incipientes. É importante também destacar que a presente investigação oferece uma contribuição gerencial no sentido de avançar o entendimento sobre o comportamento do consumidor que utiliza plataformas como a estudada. Compreender esse consumidor também se mostra importante para delimitar efeitos da troca de tempo na dinâmica dos mercados sobre os quais ela exerce algum tipo de impacto. Por esse motivo é relevante um estudo que aprofunde no valor percebido entre os usuários que participam da comunidade de troca de tempo.

\section{ECONOMIA COMPARTILHADA}

O consumo sempre existiu e fez parte dos costumes e hábitos dos seres humanos, no começo das civilizações, consumir atendia as necessidades básicas do ser humano, porém a partir do século $\mathrm{XX}$, o ato de consumir cresceu substancialmente pois passou a atender também aos demais desejos e vontades do homem (Maurer, Figueiró, de Campos, da Silva, de Barcellos, \& Dutra, 2015). 
Porém esse alto nível de consumo dos dias atuais, chamado de hiperconsumo (Vouga, 2017), é visto com insustentável devido à baixa quantidade de recursos naturais ainda disponíveis (WWF, 2012).

É nesse contexto que a economia compartilhada ganha forças como uma alternativa sustentável ao movimento de hiperconsumo. A economia compartilhada teve início nos anos 1990, nos Estados Unidos, em função de uma série de fatores, mas certamente os avanços na informática (e transações online) tiveram papel preponderante (Shirky, 2012).

$\mathrm{Na}$ academia, a partir de 2014 a literatura começa a ganhar corpo. Autores como Belk (2014), Möhlmann (2015), Piscicelli, Cooper e Fisher (2015), Habibi, Kim e Laroche (2016) e Lawson, Gleim, Perren e Hwang (2016) estudaram a nova filosofia de consumo e os novos modelos de negócio. Nesse contexto, também podem ser citados diversos trabalhos sobre as trocas em mercados específicos como, por exemplo: Fremstad (2017) sobre a redução de lixo; Aznar, Saveras, Galiana e Rocafort (2016), Gant (2016) e Tussyadiah e Pesonen (2016) sobre o turismo e hospitalidade; Fuentes-Bracamontes (2016) sobre o setor de energia; Einav, Farronato e Levin (2016) sobre o mercado peer-to-peer; de Shaheen, Chan e Gaynor (2016) sobre a troca de carros; de Cohen e Munoz (2016) sobre consumo e produção sustentáveis; e Nerinckx (2016) sobre o mercado de trabalho.

De acordo com Habibi, Davidson e Laroche (2017), a expressão economia compartilhada cresceu e se tornou um termo abrangente para uma ampla gama de formas de não-propriedade de atividades de consumo, como permuta, intercâmbio, negociação, aluguel, compartilhamento e troca. Além destes termos, a literatura também menciona a economia de acesso (Bardhi \& Eckhardt, 2012), peer-to-peer economy, access-based consumption (Lawson, Gleim, Perren, \& Hwang, 2016), consumer participation (Belk, 2014), sharing economy, e collaborative economy. A variedade de nomenclaturas e definições evidenciam que o tema ainda não está consolidado academicamente. Além disso, apesar de um espectro de relações tão amplo, há limitações sobre o conhecimento empírico de como o comportamento do consumidor deve ser gerenciado na economia compartilhada.

Botsman (2010) acredita que a combinação entre a crise mundial, a pressão para solucionar problemas ambientais e a renovação da crença nas comunidades por meio das plataformas digitais impulsionaram o surgimento dos primeiros negócios da economia colaborativa moderna. Baseadas na troca, no compartilhamento e aluguel de bens ou serviços, empresas e startups estão conectando milhões de pessoas que possuem bens ou serviços com milhões de outras pessoas que buscam apenas o acesso a tais bens e serviços, garantindo assim os benefícios que os bens ou serviços trazem para os consumidores sem a necessidade da posse (Botsman \& Rogers, 2010).

Uma nova forma de relacionamento entre os atores da troca é criada e passa a ser definida pela reputação, pela comunidade, por aquilo que podem acessar, pelo modo como compartilham e doam. Os consumidores passam a ser mais protagonistas em suas compras e no processo de decisão, e assim buscando pagar pelo acesso ao produto e experiência de tê-los temporariamente, ao invés de adquiri-lo (Bardhi \& Eckhardt, 2012). Segundo Botsman (2010), o mercado colaborativo contempla 3 tipos de sistemas:

- Sistema de produto e serviço, que elimina a necessidade de o consumidor pagar pelo produto, podendo apenas aproveitar a experiência que este produto fornece (Exemplos: Uber, Airbnb e Tem Açúcar?).

- Mercado de redistribuição, que realoca produtos parados para lugares onde possam retomar sua função fim (Exemplo: Enjoei).

- Lifestyle colaborativo, que é o compartilhamento de dinheiro, habilidades e tempo (Exemplos: Wikipedia, Bliive).

$\mathrm{O}$ presente estudo investiga o lifestyle colaborativo, ou seja, o compartilhamento de recursos que podem ser conhecimento, habilidades, atividades e o próprio tempo. A Bliive é uma rede social colaborativa que se enquadra nesse segmento da economia compartilhada. A rede propõe a seus usuários a troca de tempo por meio de uma moeda virtual que circula em sua comunidade chamada "Time Money". Desta forma, a Bliive, como uma rede social, conecta pessoas interessadas em trocar experiências/aprendizados em sua plataforma.

\section{BANCO DE TEMPO}

A ideia de troca de tempo ou Banco de Tempo surge em meados de 1980 como uma alternativa para pequenas comunidades para ajudar os grupos marginalizados, sendo também uma alternativa para os momentos de crises (Collom, 2007). 
Organizações offline foram criadas para reunir pessoas afim de trocar bens e serviços por meio de uma moeda fictícia, que só pode ser utilizada dentro da comunidade.

O Banco de Tempos então reconhece as pessoas como ativos, promovendo igualdade e aumentando a força de comunidades. Aumentando a colaboração entre jovens, adultos e idosos e como consequência diminuindo a competição apresentada pelo mercado de trabalho convencional. Um dos principais valores dessas comunidades é a reciprocidade, o fundador da Time Bank, Edgar Cahn (2010) acredita que esse valor é o que dá mais sentido à vida das pessoas que participam e garante um aumento de confiança entre os seus membros.

Com o avanço das tecnologias, foram desenvolvidos novos modelos mais sustentáveis de Banco de Tempo como a Timerepublik, SkillShare e a Bliive. Seus usuários conseguem realizar a troca de conhecimentos, experiências e atividades, de forma colaborativa com outros membros da comunidade por meio dessas plataformas digitais. Para o melhor entendimento dessa modalidade de troca dentro do contexto da economia compartilhada desenvolveu-se uma análise sob a ótica do conceito de valor percebido pelo cliente.

\section{VALOR PERCEBIDO PELO CLIENTE}

O valor percebido pelo cliente (VPC) é um instrumento utilizado para o entendimento do valor de uso para o cliente, como forma de esclarecimento das perspectivas da compra. Ele é percebido pelos consumidores, e não é determinado objetivamente pela empresa, e inclui benefícios e sacrifícios percebidos (Zeithaml, 1988).

O conceito de valor percebido pode ser entendido por meio de duas abordagens: unidimensional (global) e multidimensional (analítica). A abordagem unidimensional ou global entende o valor percebido apenas como a relação entre os benefícios e sacrifícios ligados ao consumo, tangíveis e intangíveis, e parte do pressuposto de que o consumidor visa a maximização da utilidade no processo de troca (Zeithaml, 1988).

Já a abordagem multidimensional ou analítica compreende o valor percebido por meio de diferentes atributos ou dimensões interrelacionados. A abordagem multidimensional se mostra importante para a criação de um valor superior, diferenciado da concorrência, gerando vantagem competitiva sustentável para as empresas. Ela ultrapassa a ideia de valor da teoria econômica, segundo a qual existe apenas a relação entre a qualidade recebida e o preço pago, pois essa ideia não capta o valor completo que os produtos e serviços possuem para os consumidores. Desta maneira, se faz necessária a análise de várias dimensões, cada uma com diversas características relacionadas entre si, sejam elas funcionais, simbólicas, epicuristas, estéticas, abrangendo então um fenômeno complexo que é o valor percebido pelo cliente (Sweeney \& Soutar, 2001; Fernández \& Bonillo, 2007).

Quando analisados diversos estudos empíricos, o valor percebido se apresenta mais complexo e distinto dos conceitos de qualidade e satisfação. A qualidade é o meio de se obter valor e a satisfação é a resposta emocional da entrega de valor, sendo avaliada após a compra/utilização. Valor percebido, por outro lado, pode ser medido antes, durante e depois do consumo (Galhanone, 2013).

$\mathrm{O}$ estudo bibliográfico dos autores que adotaram a abordagem multidimensional é apresentado na tabela 1 , junto com os as dimensões propostas para o constructo. Como se evidencia, não há unanimidade quanto às dimensões que compõem o valor percebido.

Tabela 1

\begin{tabular}{l|l}
\multicolumn{2}{l}{ Abordagem Multidimensional do Valor Percebido } \\
\hline Autor & Dimensão \\
\hline Sheth, Newman, \& Gross & Valor social \\
$(1991)$ & Valor emocional \\
& Valor funcional \\
& Valor epistêmico \\
& Valor condicional \\
\hline Groth $\left(1995^{\text {a }}, \mathrm{b}\right)$ & Cognitivo: utilidade percebida \\
& Psicológico \\
& Interno \\
& Externo \\
\hline
\end{tabular}




\begin{tabular}{l|l}
\hline Grönroos (1997) & Cognitivo \\
& Emocional (psicológico) \\
\hline Ruyter, Wetzels, Lemmink, & Dimensão emocional ou valor intrínseco \\
\& Mattson (1997) & Dimensão functional ou valor extrínseco \\
& Dimensão lógica \\
\hline Sweeney, Soutar, \& Johnson & Valor social (aceitabilidade) \\
& Valor emocional \\
& Valor funcional (preço/valor pelo dinheiro) \\
& Valor functional (desempenho/qualidade) \\
& Valor functional (versatilidade) \\
\hline Sweeney \& Soutar (2001) & Dimensão functional (econômico e prático) \\
& Dimensão social \\
& Dimensão emocional \\
\hline
\end{tabular}

Fonte: Adaptado de Sanchez, Callarisa, Rodriguez, \& Moliner (2006)

A abordagem multidimensional escolhida para este estudo foi a de Sheth, Newman e Gross (1991) que identificaram cinco valores que influenciam o comportamento de compra de maneiras diferentes. Esses valores são independentes, porém podem influenciar as decisões isoladamente ou em conjunto. Os valores são:

- Valor Funcional - Relacionados aos a atributos utilitários, funcionais e físicos, como especificações técnicas e a qualidade do produto e serviço. Exemplo: desempenho, confiabilidade, qualidade, preço e durabilidade.

- Valor Social - Resultado de uma associação com grupos demográficos, socioeconômicos e culturais que podem estar relacionadas positiva ou negativamente com os estereótipos.

- Valor Emocional - a capacidade de provocar sentimentos, estados afetivos ou reações emocionais. Exemplo: conforto, segurança, paixão, medo, culpa, amizade.

- Valor Epistêmico - a capacidade de provocar a curiosidade, de oferecer novidade, de estimular ou satisfazer um desejo por conhecimento, promover novas experiências ou mudanças.

- Valor Condicional - Resultado de antecedências físicas ou eventualidades sociais que aumentam o valor funcional ou social, mas que não possuía esse valor fora desse contexto. Específica da situação em que o decisor se encontra.

Os autores argumentam que a teoria se aplica para bens duráveis, não duráveis, industriais e serviços. A partir da teoria de Sheth, Newman e Gross (1991), os autores Sweeney e Soutar (2001) desenvolveram uma escala multi-item, que foi denominada PERVAL (PERceived VALue scale), mantendo três dimensões do modelo (funcional, social e emocional). A PERVAL é uma das medidas de valor percebido pelo consumidor já estabelecidas que foram testadas em vários tipos de negócio.

Muitas escalas de mensuração de valor percebidas pelo cliente, como a PERVAL, procuram examinar o valor como um processo linear, em que o valor é percebido em pré e pósfases de consumo de serviço (Sweeney \& Soutar, 2001) ou simplesmente como um juízo de valor com base na experiência em uso. Os questionários de valor percebido pelo cliente são normalmente preenchidos durante ou após situação de uso do serviço.

A mensuração dedutiva de categorias de valor predefinidas é útil nestes momentos/contextos, porque este tipo de medida de valor percebido pelo cliente pode ser usado para estimar o efeito de valor percebido pelo cliente em outros construtos, como fidelidade do cliente ou em suas intenções de compra.

Sweeney e Soutar (2001) começaram a escala com 85 itens, e após um refinamento chegaram a 19 itens agrupados em quatro dimensões: valor emocional, valor social e valor funcional, este último dividido entre preço e qualidade. A escala PERVAL foi assim validada pelos autores para estudar o valor percebido de bens duráveis. $\mathrm{O}$ valor epistêmico foi eliminado por não ser relevante para o estudo de bens duráveis, e estar mais associado ao estudo de serviços e experiências e o valor condicional por ser específico de situações de efeito sobre outro valor. A principal contribuição de Sweeney e Soutar (2001) foi a análise de qualidade e preço separadamente e, admitindo assim que essas dimensões podem estar relacionadas na mesma situação de consumo. 
Ainda que a dimensão epistêmica possa ser relevante para o estudo da troca de tempo, pois está relacionada à curiosidade e ao desejo de conhecer, preferiu-se estudar o valor percebido pelos usuários da rede Bliive a partir da conceituação de Sheth, Newman e Gross (1991) - funcional, social e emocional - e colocados em uma escala (PERVAL) por Sweeney e Soutar (2001), pois segue um rigoroso processo de preparação e permite o teste empírico das dimensões do valor percebido.

\section{MÉTODO EMPÍRICO}

Levando em consideração que o objeto de estudo ainda é pouco conhecido, foi utilizado o método exploratório qualitativo para levantar novas hipóteses sobre o valor percebido em uma rede de troca de tempo. Este método proporciona uma maior descoberta pois através das palavras, ideias e imagens coletadas é possível identificar padrões, hipóteses e obter insights sobre o tema (Hair, Babin, Money, \& Samouel, 2005).

A técnica de coleta de dados foi a de entrevista em profundidade, semiestruturada. Essa técnica permite a compreensão das atitudes, valores e motivações dos entrevistados (Minayo, 2008). Para um melhor direcionamento aos constructos do valor percebido pelo cliente, foi elaborado um roteiro de entrevista com algumas perguntas sugeridas.

Para compreender as dimensões do valor percebido foi utilizada a teoria de Sheth, Newman e Gross (1991) que identificaram cinco valores que influenciam no comportamento de compra. As dimensões apresentadas pelos autores são as de valor funcional, emocional, social, epistêmica e causal.

No entanto, os construtos do valor epistêmico e valor causal não foram utilizadas no estudo. Durante a revisão bibliográfica, não foi identificada uma métrica confiável, validada e consolidada na academia para o valor epistêmico. Já o valor causal não se enquadra no estudo, pois a investigação não focou em uma circunstância pontual que possa ter causado alguma alteração nas demais dimensões de valor.

No intuito de compreender as dimensões do valor percebidos pelos usuários da rede de troca de tempo, Bliive, foi utilizada a própria plataforma e redes sociais para identificar os usuários para as entrevistas. O quadro 1 mostra as informações básicas dos usuários entrevistados.

\begin{tabular}{|c|c|c|c|}
\hline Nome & Sexo & Idade & $\begin{array}{c}\text { Quantidade de transações } \\
\text { realizadas por meio da plataforma }\end{array}$ \\
\hline LR & Homem & 22 & 3 \\
\hline NM & Mulher & 25 & 1 \\
\hline LS & Mulher & 27 & 2 \\
\hline JB & Mulher & 29 & 3 \\
\hline TS & Mulher & 29 & 1 \\
\hline GN & Homem & 31 & 1 \\
\hline MR & Mulher & 32 & 13 \\
\hline HO & Homem & 34 & 11 \\
\hline RS & Homem & 37 & 1 \\
\hline RO & Mulher & 37 & 14 \\
\hline LS & Mulher & 39 & 0 \\
\hline ML & Mulher & 45 & 6 \\
\hline RR & Homem & 59 & 3 \\
\hline
\end{tabular}

Fonte: Dados da pesquisa.

Quadro 1: Relação de respondentes

Foram entrevistados 13 usuários da rede Bliive, sendo 5 do sexo masculino e 8 do sexo feminino. Os usuários da rede Bliive estão dispersos demograficamente por todo o mundo, porém os respondentes escolhidos em sua maioria se encontram em território brasileiro, apenas uma entrevistada que morava fora do país. Todos os respondentes já tiveram algum contato com a plataforma, não necessariamente continuando inscritos/ativos. Apenas uma respondente (LS) não chegou a realizar trocas. E um respondente $(\mathrm{HO})$ disse não utilizar mais a rede de trocas de tempo.

Durante os meses de setembro e outubro de 2017 os respondentes foram convidados para uma entrevista. Dependendo da disponibilidade dos respondentes, as entrevistas ocorreram ou por meio virtual, via Skype, ou pessoalmente, em encontros 
marcados, com uma duração média de 30 minutos a 01 hora.

Levando em consideração o problema de pesquisa e objetivo foi realizada uma análise de conteúdo simplificada a partir das transcrições das entrevistas e dos temas abordados no referencial teórico.

\section{RESULTADOS}

Para melhor entendimento dos resultados, a pesquisa foi desenvolvida com 3 blocos de perguntas voltadas a cada dimensão do valor percebido pelo cliente. Desta maneira, a primeira dimensão analisada foi a do valor funcional. Esta dimensão se propõe a entender os aspectos funcionais que a plataforma de troca de tempo pode apresentar.

\section{Valor funcional}

De acordo com Sheth, Newman e Gross (1991), o valor funcional está na capacidade funcional $\mathrm{e}$ utilitária de determinado serviço e produto, o entendimento do mesmo também se faz necessário. De modo geral os usuários da Bliive entrevistados demonstraram entender o conceito de troca de tempo onde a plataforma se propõe a conectar dispostas a compartilhar seus conhecimentos e experiências como mencionado por RS "A ferramenta te possibilita fazer um encontro das duas partes (Quem está oferecendo alguma experiência e quem está procurando)". A proposta da plataforma é atingida de forma que todos os usuários realizem as trocas de tempo de forma eficaz como disse MR: "Plataforma simples e rápida de usar".

Foi identificado também uma funcionalidade alternativa à da proposta pela Bliive, em que alguns usuários participam da plataforma a fim de oferecer seus conhecimentos e serviços como uma amostra grátis e assim aumentar a sua rede de clientes. RO explicou que "Muitas pessoas entram na plataforma para apresentar o seu serviço, dessa forma elas limitam em duas ou três sessões (trocas) para que você faça a compra futuramente do serviço completo". Identificou-se, assim, uma utilidade para a plataforma que vai além da troca de tempo, essa também é utilizada como uma vitrine para profissionais. TS comentou que:

$\mathrm{Na}$ questão de oferecer aula, é como entregar cartão de visita, até você ficar conhecido. Então a plataforma acaba virando um facilitador para você conseguir sua clientela (TS).
Desta maneira, foi identificado que as diferentes expectativas dos usuários com a plataforma geraram dois diferentes tipos de usuários com diferentes ideias da funcionalidade de troca de tempo. O primeiro é o usuário casual que está compartilhando um de seus conhecimentos por prazer. E o segundo está compartilhando seus conhecimentos como forma de divulgação de um serviço pago fora da plataforma.

Dentro da plataforma existe uma grande diversidade de experiências oferecidas que enriquecem as experiências dos usuários e aumentam a possibilidade de os mesmos encontrarem alguma troca que satisfaça seus desejos. Quando questionado sobre o que mais chamou atenção na plataforma, $\mathrm{HO}$ respondeu que "A quantidade de coisas que consideramos fúteis que são oferecidas de maneira séria na plataforma".

No entanto toda essa diversidade de experiências oferecidas tem seu valor igualado em um mesmo denominador comum, a moeda da plataforma "Time Money". E assim uma hora trocada para aprender inglês vale o mesmo que ter uma companhia para passear no parque, duas atividades que fora da plataforma não obteriam o mesmo valor de troca, se equiparam dentro dessa comunidade. O tempo como uma moeda de troca é entendido então como uma vantagem nas relações de troca, RO comentou: "Equiparar os valores dos serviços, nem desvaloriza sua hora, nem supervaloriza a hora do outro".

Quanto a qualidade das ofertas da plataforma ML acredita que "Não tem como você garantir, mas depende da boa vontade das pessoas", porém a mesma complementou:

Como a pessoa que oferece uma troca se dispõe a fazer, não está trabalhando, não tem a obrigação. Assim a troca fica muito mais tranquila e gostosa. Ela está ensinando uma coisa que ela gosta de fazer, assim fica ainda mais disposta a ensinar (ML).

Essa opinião foi compartilhada por outros respondentes como NM, para quem:

Não tem muito como garantir a qualidade, é uma plataforma que trabalha na boa fé e na boa vontade das pessoas, acho que pode ser um ponto muito legal, mas também pode ser um ponto que pode destruí-la (NM). 
Dessa forma, uma respondente citou uma opção para garantir que a qualidade não fosse apenas baseada na avaliação de 0 a 5 estrelas:

As pessoas que estão querendo fazer a troca comigo não sabem nada, só sabem aquele mini texto que escrevi ali e não tem como garantir qualidade das minhas aulas, mas as pessoas que já tiveram mais trocas têm as estrelas para ver se foi boa a troca ou não. Poderia assim existir um espaço para comentários. Ou, por exemplo, eu poderia ter colocado minha nota do TOEFL, ou ter colocado meu certificado de conclusão do curso de inglês, ou meu currículo para as pessoas saberem que eu já trabalhei com Excel e Powerpoint, as pessoas têm que confiar no que eu escrevi lá (NM).

Em contrapartida o respondente $\mathrm{HO}$ acredita no oposto. Ele comentou: "O que faz uma experiência ter qualidade é a vontade e a intenção das pessoas, não são títulos que fazem as pessoas serem melhores profissionais."

Assim sendo, percebeu-se que os usuários reconhecem que o valor do seu tempo doado é inestimável, então para disponibilizar esse tempo para outras pessoas é porque querem mesmo compartilha-lo, gerando assim uma troca de qualidade. ML exemplificou: "Pego uma coisa que eu gosto muito de fazer e doou para outra pessoa que tem interesse."

Sobre a confiabilidade nas trocas os entrevistados demonstraram bastante segurança quanto as trocas que já realizaram. Alguns respondentes mencionaram alguns cuidados que tomam para garantir maior segurança:

Acho que é uma questão igual a qualquer outra rede social, como o Tinder ou Happn. Então tem que tomar alguns cuidados, por isso quando é aula ao vivo, eu não vou na casa da pessoa e programo ir em locais públicos como bibliotecas (TS).

Para mim tem que se encontrar em locais públicos mesmo, ou procurar a pessoa em outras redes sociais como o Facebook ou LinkedIn. Hoje em dia tudo tem um pouco desse lado, na Uber, ou Airbnb, você não sabe quem vai ser a pessoa que vai estar ali. Só que conforme for utilizando mais e tendo mais avaliações as pessoas vão ficando mais seguras (NM).

A plataforma apresenta instrumentos que garantem a confiabilidade de seus usuários, como as descrições fornecida em cada experiência, a avaliação de outras trocas já realizadas e o próprio chat que é aberto ao solicitar uma troca, que serve para esclarecer qualquer dúvida restante $\mathrm{e}$ encontrar o melhor horário ou local para realizar as trocas.

Estes foram os aspectos da dimensão funcional explorados nas entrevistas. O próximo item analisa a dimensão do valor emocional, que buscou entender os sentimentos e reações emocionais que os usuários da rede Bliive sentiram ao estar em contato com a plataforma.

\section{Valor emocional}

Para Sheth, Newman e Gross (1991) esta dimensão é definida pela capacidade de o produto ou serviço gerarem sentimentos ou estados afetivos. Desta maneira, ao serem questionados quanto aos seus sentimentos em realizar as trocas os respondentes apresentaram o sentimento de gratidão de compartilhar suas experiências ou até mesmo em se relacionar com outros usuários, como se evidencia pelas transcrições a seguir:

Me senti feliz. Me senti muito útil. Pude ajudar um jovem a aprender como consertar a moto dele e em troca aprendi sobre coaching. No fundo acredito que seja a mesma sensação de quando se faz trabalho voluntário (RR).

Sentimento de gratidão. Conheci pessoas maravilhosas na plataforma com as quais pôde aprender tantas coisas que até ontem não imaginava poder aprender (MR).

Me sinto feliz por estar oferecendo meus conhecimentos para alguém que eu provavelmente não teria contato $(\mathrm{JB})$.

Sheth, Newman e Gross (1991) afirmam que o valor emocional frequentemente está associado à ligação entre o produto e serviço com causas sociais. A oportunidade de compartilhar com outras pessoas gerou sentimentos de utilidade a sociedade como relatou LK: "senti autossatisfação em ajudar a pessoa com o que eu sabia, então me senti helpfull, útil". Essa sensação de utilidade vem da valorização dada as experiências compartilhadas, MR conta o que sentiu "Me senti importante. Fazer parte de algo onde a minha experiência fosse valorizada por outras pessoas". Em sua entrevista, RO expôs que a valorização de seu próprio conhecimento "Eu estou ofertando uma hora minha, e uma hora minha custa caro". 
Em contrapartida alguns respondentes apontaram algumas situações frustrantes em suas trocas por elas não envolverem nenhum valor monetário. Nesse sentido, HO comentou: "Parei de usar a plataforma pela falta de comprometimento das pessoas, não dão satisfação, só por que é gratuito, não preciso ir". Em outra situação RO comentou sobre sua frustração:

Alguma pessoa tem problema para entender o processo de comprometimento. Por ser de graça, as pessoas marcam e não vão. Nós não valorizamos o gratuito e a nossa própria hora (RO).

As trocas que acontecem geralmente fora da plataforma, ou por meio de aplicativos como WhatsApp, Facebook e Skype ou presencialmente. Assim as trocas podem causar em alguns usuários alguma insegurança na hora de realizar a troca, LS disse ter sentido "um desconforto do primeiro contato com um desconhecido". ML também comentou sobre esse primeiro contato na hora da troca: "Uma sensação de primeiro dia de aula. Você já está lá e tem que fazer acontecer". ML também acrescentou a importância que sente quanto as trocas presenciais que realizou: "As trocas presenciais é uma das coisas mais bacanas da plataforma. Você se abdicar do meio digital e encontrar as pessoas. Um movimento de retomada do contato humano".

Essa insegurança entre os usuários também se mostrou presente na hora de ofertar suas experiências na plataforma, como conta LS, que diz ter sentido "insegurança para oferecer algum serviço, insegurança com os meus conhecimentos". Sobre alguns perfis da rede, HO comentou que: "Eu vi também bastante gente na plataforma que é tão insegura que não consegue oferecer nada". NM também contou como foi sua experiência e como se sentiu ao compartilhar seus conhecimentos:

Acho que vai ser importante, porque pode ajudar a me julgar um pouco menos, quando eu vi que deveria oferecer coisas que eu era expert eu fiquei "meu deus, não sei de nada", essa foi a minha primeira reação. (...) fico apreensiva no sentido de "será que vou ser suficiente para o que a pessoa está esperando", mas ao mesmo tempo por não ter a troca financeira eu me sinto mais tranquila porque a pessoa está ali (na plataforma), tem a expectativa de querer trocar, mas ela também não está com uma grande expectativa porque senão ela estaria investindo. Então acho que por ser uma troca de horas e não ser financeira tira um pouco do peso e pode me ajudar. E eu gosto quando eu consigo ajudar as pessoas. É mais fácil porque é one to one, se fosse uma turma acho que não conseguiria (NM).

Outro sentimento relatado foi $o$ de pertencimento a uma comunidade, já que os usuários que participam da plataforma identificaram que compartilham do mesmo interesse que os demais membros da comunidade que se relacionam. Sobre isso, LK comentou: "o que eu sinto é que são pessoas como eu, que tem uma visão, que acreditam em algo, algo diferente que não é aquele mundo voltado para grana, onde o dinheiro coordena". Esse sentimento também se relaciona com a dimensão social do valor percebida que será analisada em seguida.

\section{Valor social}

Sobre o valor social Sheth, Newman e Gross (1991) o definem como uma utilidade adquirida a partir da associação de uma alternativa ou escolha com um ou mais grupos sociais. Esta associação pode ser positiva ou negativa, estereotipada, demográfica, socioeconômica ou cultural-étnica. Desta maneira, esse bloco das entrevistas se inicia com a pergunta "Você acredita que a troca de tempo possa trazer algum bem para a sociedade?" e a resposta foi "sim" para todos os respondentes. E assim surgiram algumas opiniões sobre o que seria esse bem à sociedade.

Alguns respondentes mencionaram uma nova forma de relacionamento entre as pessoas, quando os interessem em comum são levados em consideração nas relações, tornando-as mais saudáveis, como comentou NM:

A possibilidade de conhecer pessoas novas de
uma forma interessante porque ambos têm
interesses em comum na troca, então já se cria
um vínculo que facilita essa interação e a
possibilidade de aprender coisas diferentes de
forma fácil sem ter que investir
financeiramente para isso (NM).

ML também percebeu que a conexão entre pessoas com interesses em comum foi beneficial para o seu aprendizado: "Conhecer uma pessoa nova que talvez não tenha nada parecido com você é uma experiência muito interessante, e juntando com apreender alguma coisa foi muito produtivo".

De acordo com RO, a conexão entre as pessoas pode expandir o círculo social dos indivíduos: "Aumentei a minha rede de pessoas, fiz um networking através das minhas solicitações". 
Essa conexão entre as pessoas, seja ela online ou presencial gerou também uma valorização dos diferentes trabalhos e conhecimentos. ML dá um exemplo de como uma de suas trocas a fizeram perceber isso:

Por exemplo, quando você apreende a fazer pão e aí vai na padaria e vê o preço, você entende o quanto as coisas custam, o trabalho que dá produzi-lo, te ajuda a entender a relação das coisas. E assim você acaba valorizando o trabalho do outro (ML).

Outro benefício apontado é a democratização do conhecimento. Sobre o tema, RO comentou que o formato da troca de tempo fornece "Acesso colaborativo; não preciso ter dinheiro, eu tenho o meu tempo". Apesar disso, é importante destacar que para ser um usuário da Bliive é necessário ter acesso a um computador ou smartphone com acesso internet. Este aspecto não é mais uma grande barreira, pois, como foi apontado na pesquisa da PwC (2014), o acesso à internet está cada vez mais disseminado por todo o mundo.

A democratização da informação pode beneficiar pessoas que buscam aumentar seu leque de conhecimentos e habilidades. Além disso, ela também possibilita a experimentação de certo conhecimento por diversos grupos na sociedade. $\mathrm{O}$ relato de RO evidencia esta faceta da troca de tempo: "A troca de experiências podem ajudar as pessoas, dar um caminho para seguirem. Ajudar novos talento a se desenvolverem, ONGs, profissionais que estão iniciando ou se recolocando no mercado de trabalho e pessoas de baixa renda".

Quando perguntados sobre o perfil dos membros da comunidade muitos responderam acreditar que o público alvo são os jovens. No entanto, o respondente RR comentou: "A maioria são todos jovens. Acredito que a plataforma seja mais voltada para o público jovem, porém acho interessante eles explorarem também o público mais velho". O público jovem pode ter mais facilidade com a tecnologia, mas existem também usuários mais velhos compartilhando conhecimentos na rede Bliive, como alguns dos respondentes encontrados, ML, de 45 anos, e RR, de 59 anos.

Outros respondentes acreditam que o perfil dos usuários não é tão limitado, e está mais relacionado com um lifestyle colaborativo. De acordo com NM, o usuário da Bliive pode ser "Todo mundo que tem interesse em aprender alguma coisa". Já para LK, o perfil é um pouco mais homogêneo. Ele acredita que são "pessoas que têm uma visão de mundo diferente, que estão em busca de viver sem influência do dinheiro e pra isso querem usar o que sabem em troca de aprender". De certa forma, ML corrobora esta opinião, ao comentar que a Bliive é composta por "Pessoas que estão mudando seu estilo de vida, menos consumistas, uma alimentação mais saudável e cuidando da natureza".

Outros respondentes também mencionaram perceber na plataforma uma mudança no estilo de vida entre seus usuários. Essa mudança está pautada em novos hábitos relacionados ao compartilhamento de bens e experiências e diminuição do consumo, características do lifestyle colaborativo, como é mostrado nos comentários abaixo:

É um sentimento de felicidade de ver que existe uma mudança no mindset de estar aberto a ensinar uma coisa que eu sei que pode ser interessante para alguém e também eu possa conseguir algo em troca depois, porque eu posso trocar por alguma coisa que eu queira aprender (NM).

Existe uma mudança de pensamento, uma mudança da relação das pessoas com o dinheiro, a valorização das trocas. A plataforma te dá uma opção de estilo de vida, de ser um pouco mais slow, ir um pouco mais devagar no que faz, não ser tão consumista, não tão ligado no dinheiro, e sim na troca de humanidade mesmo. (ML).

Essa associação dos usuários da plataforma com a imagem do lifestyle colaborativo está de acordo com a teoria do valor social de Sheth, Newman e Gross (1991), que afirmam que esse valor pode ser medido por um perfil de imagem escolhido, no caso o perfil de participar de um lifestyle colaborativo.

Após as análises e considerações sobre os relatos coletados, tendo avaliado as três dimensões do valor percebido pelos usuários da rede de troca de tempo Bliive que este artigo se propôs a considerar, passa-se para as considerações finais da pesquisa.

\section{CONSIDERAÇÕES FINAIS}

Com base nas análises realizadas, esse capítulo apresentará as considerações finais e sugestões para trabalhos futuros. Para compreender o valor percebido dos integrantes da rede troca de tempo Bliive, e o quanto esses valores os mantêm 
engajados utilizando a plataforma, foi considerado o modelo proposto por Sheth, Newman e Gross (1991), valor funcional, social e emocional.

Desta forma considerou-se que para os usuários da rede Bliive a funcionalidade que a plataforma oferece de conectar pessoas com interesses em comum para compartilhar experiências é um atrativo para que as pessoas se inscrevam na plataforma, porém para que permaneçam ativas na rede se faz necessário o senso pertencimento a uma comunidade de troca de tempo, e assim incluir o lifestyle colaborativo no estilo de vida. Essa característica em comum encontrada nos respondentes mostrou quão relevante esse fator social é para que os usuários se mantenham engajados na plataforma.

De modo geral, os entrevistados encontram utilidade na plataforma e entendem esse novo modelo de troca proposto, a troca de tempo. Foram identificadas diferentes formas de utilização da plataforma; elas variam de acordo com as expectativas dos usuários. Existem usuários que querem compartilhar suas experiências e conhecimentos, assim como aqueles que buscam novas experiências e aprendizados. Mas uma terceira funcionalidade da rede mostrou-se relevante como a utilização da plataforma por profissionais para realizar uma demonstração do seu serviço para potenciais clientes.

A qualidade e confiabilidade das trocas relatadas pode ser tida como um incentivo a se manter engajado a comunidade. Já que os respondentes se mostraram satisfeitos com as trocas realizadas e pontuaram fortemente que quem se propõe a doar o seu tempo, está fazendo isso com prazer. Assim como a conexão das pessoas por meio de interesses em comum se mostrou um fator que torna as trocas mais gratificantes.

Outro ponto que incentiva o engajamento dos membros da comunidade é oportunidade de expandir o seu ciclo social, vivenciar novas experiências e valorizar as diferentes atividades ofertadas na plataforma.

Também foram identificados alguns valores que podem inibir a participação na plataforma. $\mathrm{O}$ sentimento de insegurança para compartilhar seus conhecimentos e se relacionar com outras pessoas. Assim como a falta comprometimento das pessoas com o tempo, um bem muito valorizado e escasso, mas que quando relacionado as trocas tempo pode ser facilmente deixado de lado pelos usuários, o que pode dificultar a realização de algumas trocas.

Deste modo, a partir do pressente estudo realizado para entender as três dimensões do valor percebido pelo cliente da plataforma de troca de tempo, chega-se à conclusão que o mindset do lifestyle colaborativo, encontrado como um valor social nos membros da rede, é de extrema relevância para que esses mantenham-se engajados.

A ideia funcional da plataforma que é conectar pessoas que compartilhem do mesmo interesse para trocarem experiências por meio do tempo se mostra com uma alternativa para as trocas na sociedade. Essa funcionalidade da plataforma é um diferencial que atraí as pessoas, mas não é essa funcionalidade que garante o engajamento dos usuários. Desta maneira, o engajamento dos usuários se mostrou mais relacionado aos benefícios sociais que esses enxergam, como a conexão com pessoas de interesses em comum, a ideia de compartilhar experiências e conhecimentos e assim ajudar ao próximo, ajudar a sociedade.

Para trabalhos futuros indica-se a utilização da escala PERVAL como métrica para uma pesquisa quantitativa sobre o valor percebido pelos usuários de plataformas de troca de tempo. A investigação de outras plataformas também é importante para que os resultados possam ser comparados, buscando-se o estabelecimento de padrões no comportamento do consumidor. $\mathrm{O}$ aprofundamento do estudo na dimensão do valor epistêmico proposto por Sheth, Newman e Gross (1991), e a eventual criação de uma nova escala para a medição desta dimensão são outros possíveis caminhos investigativos. Por último, sugere-se pesquisar o impacto das redes de trocas de tempo nos mercados de serviços pagos.

\section{REFERÊNCIAS}

Aznar, J. P., Sayeras, J. M., Galiana, J., \& Rocafort, A. (2016). Sustainability commitment, new competitors' presence, and hotel performance: the hotel industry in Barcelona. Sustainability, $8(8), 755$.

Bardhi, F., \& Eckhardt, G. M. (2012). Access-based consumption: the case of car sharing. Journal of Consumer Research, 39, 881-898.

BBC. (2012). Crise traz de volta a prática de escambo na Europa. Recuperado dehttp://www.bbc.com/portuguese/noticias/2012/ 01/120119_escambo_espanha_ai.shtml

Belk, R. (2014) You are what you can access: Sharing and collaborative consumption online. Journal of Business Research, 67, 1595-1600.

Botsman, R. (2010). Rachel Botsman: O caso para o consumo cooperativo. Recuperado de 
https://www.youtube.com/watch?v=AQa3kUJPE ko

Botsman, R., \& Rogers, R. (2010). What's mine is yours: The rise of collaborative consumption. New York: Harper Collins.

Cahn, E. (2010). Time Bank founder Edgar Cahn. Recuperado https://www.youtube.com/watch?v=ySzlmwmiH Do

Cohen, B., \& Munoz, P. (2016). Sharing cities and sustainable consumption and production: towards an integrated framework. Journal of Cleaner Production, 134, 87-97.

Collom, E. (2007). The motivations, engagement, satisfaction, outcomes, and demographics of time bank participants: survey findings from a U.S. system. International Journal of Community Currency Research, 11, 36-83.

Credit Suisse. (2015). Equity Research: The Sharing Economy Recuperado de https://doc.researchand-

analytics.csfb.com/docView?document $\mathrm{id}=\mathrm{x} 657$ 090\&serialid=\%2BoJISdkXI8WqPDLK 1 KH $51 \mathrm{y}$ O3NdPKCzCWPXEKeyF0dQo\%3D/

Einav, L., Farronato, C., \& Levin, J. (2016). Peer-topeer markets. Annual Review of Economics, 8, 615-635.

Fernández, R. S., \& Bonillo, M. A. I. (2007). The concept of perceived value: a systematic review of the research. Marketing Theory, 7, 427-451.

Fremstad, A. (2017). Does Craigslist reduce waste? Evidence from California and Florida. Ecological Economics, 132, 135-143.

Fuentes-Bracamontes, R. (2016). Is unbundling electricity services the way forward for the power sector? The Electricity Journal, 29(9), 1620.

Galhanone, R. F. (2013). Valor percebido pelo consumidor de produtos de luxo: Proposição de um modelo teórico. (Tese de doutorado). Faculdade de Economia, Administração e Contabilidade, Universidade de São Paulo, São Paulo, SP, Brasil.

Gant, A. C. (2016). Holiday rentals: The new gentrification battlefront. Sociological Research Online, 21(3), 1-9.

Gupta, A. K., \& Govindarajan, V. (2003). Global strategy and the organization. New York, NY: Wiley.

Habibi, M. R., Davidson, A., \& Laroche, M. (2017). What managers should know about the sharing economy. Business Horizons, 60(1), 113-121.

Habibi, M. R., Kim, A., \& Laroche, M. (2016). From sharing to exchange: An extended framework of dual modes of collaborative nonownership consumption. Journal of the Association for Consumer Research, 1(2), 277-294.
Hair, J., Babin, B., Money, A., \& Samouel, P. (2005). Fundamentos de métodos de pesquisa em administração. Bookman Companhia Ed.

Lawson, S. J., Gleim, M. R., Perren. R., \& Hwang, J. (2016) Freedom from ownership: An exploration of access-based consumption. Journal of Business Research, 69, 2615-2623.

Maurer, A. M., Figueiró, P. S., de Campos, S. A. P., da Silva, V. S., De Barcellos, M. D. (2015). Yes, we also can! O desenvolvimento de iniciativas de consumo colaborativo no Brasil. Revista Base, 12(1), 68-80.

Minayo, M. C. de S. (2008). O desafio do conhecimento. 11 ed. São Paulo: Hucitec.

Möhlmann, M. (2015). Collaborative consumption: determinants of satisfaction and the likelihood of using a sharing economy option again. Journal of Consumer Behaviour, 14(3), 193-207.

Nerinckx, S. (2016, June). The 'Uberization' of the labour market: some thoughts from an employment law perspective on the collaborative economy. In ERA Forum (Vol. 17, No. 2, pp. 245-265). Springer Berlin Heidelberg.

Piscicelli, L., Cooper, T., \& Fisher, T. (2015). The role of values in collaborative consumption: insights from a product-service system for lending and borrowing in the UK. Journal of Cleaner Production, 97, 21-29

Prahalad, C. K., \& Ramaswamy, V. (2004). The future of competition: co-creating unique value with customers. Boston: Harvard Business School Press.

PWC. (2014). Consumer intelligence series the Sharing Economy. Recuperado de https://www.pwc.com/us/en/technology/publicati ons/assets/pwc-consumer-intelligence-series-thesharing-economy.pdf

Sanchez, J., Callarisa, L., Rodriguez, R. M., \& Moliner, M. A. (2006). Perceived value of the purchase of a tourism product. Tourism Management, 27(3), 394-409.

Shaheen, S. A., Chan, N. D., \& Gaynor, T. (2016). Casual carpooling in the San Francisco Bay Area: Understanding user characteristics, behaviors, and motivations. Transport Policy, $51,165-173$.

Sheth, J. N., Newman, B. I., \& Gross, B. L. (1991). Why we buy what we buy: a theory of consumption values. Journal of Business Research, 22(2), 159-170.

Schwab, K. (2016). The Fourth Industrial Revolution: what it means, how to respond. Recuperado de https:/www.weforum.org/agenda/2016/01/thefourth-industrial-revolution-what-it-means-andhow-to-respond/>

Shirky, C. L. (2012). Lá vem todo mundo: o poder de organizar sem organizações. Rio de Janeiro: Zahar. 
Sweeney, J. C., \& Soutar, G. N. (2001). Consumer perceived value: The development of a multiple item scale. Journal of Retailing, 77(2), 203-220.

Tussyadiah, I. P., \& Pesonen, J. (2016). Impacts of peerto-peer accommodation use on travel patterns. Journal of Travel Research, 55(8), 1022-1040.

Vouga, A. (2017). Influências contraculturais no consumo colaborativo: Insights no contexto do Couchsurfing.com. Consumer Behavior Review, $1(2), 73-81$
WWF. (2012). Living planet report 2012. Recuperado de

http://awsassets.panda.org/downloads/lpr_2012 summary_booklet_final.pdf

Zeithaml, V. (1988). Consumer perceptions of price, quality and value: a means-end model and synthesis of evidence. Journal of Marketing, $52(3), 2-22$.

\section{The value perceived by users in the exchange of time: the Bliive case}

Abstract: The current technological revolution has boosted the emergence of companies within the shared economy that privilege access rather than ownership. In response to hyperconsumption and the global economic crisis, a new pattern of consumer behavior called collaborative lifestyle emerges, which proposes the exchange of knowledge, skills and time between people. This paper aims at understanding the perceived value of users participating in a time-sharing platform, Bliive. For that, a qualitative exploratory research was carried out, which, through interviews with thirteen users, analyzed three dimensions of perceived value: functional, emotional and social. The analysis revealed that people engage in the network because the platform allows the connection between people with common interests, but the motive that keeps them in the system is the sense of community and the collaborative lifestyle.

Keywords: Sharing economy, Time sharing, Perceived value. 